Vol. 4, No. 2, 2019

\title{
SURFACE WASTEWATER TREATMENT FROM VARIOUS FRACTIONS OF PETROLEUM PRODUCTS FROM THE TERRITORY OF HIGHWAY INFRASTRUCTURE FACILITIES
}

\author{
Valentina Iurchenko $^{1}$, Oxana Melnikova ${ }^{1}$, Nikolay Mikhalevich $^{2}$, Oleksandra Borzenko $^{2}$ \\ ${ }^{1}$ Kharkov National University of Civil Engineering and Architecture, \\ 40 Sumskaya Str., Kharkiv, 61002 , Ukraine \\ ${ }^{2}$ Kharkiv National Automobile and Highway University, \\ 26 Petrovskoho Str. Kharkiv, 61002,Ukraine \\ yurchenko.valentina@gmail.com,mikhoksana82@gmail.com \\ mkolyag@gmail.com,saphochka1@gmail.com
}

https://doi.org/10.23939/ep2019.02.074

Received: 12.03.2019

(C) Iurchenko V., Melnikova O., Mikhalevich N., Borzenko O., 2019

\begin{abstract}
The article is devoted to the parameters of mechanical treatment of surface wastewater generated in the territory of suburban facilities of the highways from petroleum products (PPs) and their separate fractions. It is found that the open settling mode is more promising. The highest effect of treatment from PPs (within the range under study) is achieved at PPs initial concentration of $125-210 \mathrm{mg} / \mathrm{dm}^{3}$ on the third day of settling.
\end{abstract}

Key words: suburban facilities of the highways, treatment of surface wastewater from petroleum products, fractionation of petroleum products, parameters of surface wastewater settling, regression equations.

\section{Introduction}

Environmental studies of the influence of vehicles on the level of environmental safety of the roadside area are concentrated mainly on the analysis of exhaust gases emission into the atmosphere and the negative impact of noise without paying attention to high ingredient contamination of water and soil ecosystems in the territories adjacent to the highways [1]. Runoff of drain and melt water generated as a result of precipitation on the roadway coverage is one of the main sources of soil contamination in the adjacent areas [2]. By the level of MAC excess, the greatest ecological danger for groundwater and aquatic ecosystems is created by petroleum products (PPs) that enter the territory of roadside area with surface wastewater from the roadway coverage. In environmental studies, PPs are non-polar and low-polar carbohydrates soluble in hexane which are not sorbed by aluminum oxide. By a combination of properties, and, consequently, the nature of the impact on the ecosystem, PPs differ significantly from other pollutants, which is due to the heterogeneity of the chemical composition of PPs. It is found that carbohydrates with the temperature of boiling from $150^{\circ} \mathrm{C}$ to $275^{\circ} \mathrm{C}$ are the most toxic $[3,4]$.

Technical solutions concerning drain water treatment are actively developed abroad and in Ukraine using the sewage facilities for industrial and urban wastewater treatment [5]. However, despite the presence of a number of engineering developments on the arrangement of surface water removal system, the issues of both typical and individual design of water removal and wastewater treatment at the highway objects (taking into account economic and environmental factors) require clarification and refinement. The urgency of this problem has increased especially in connection with the need for harmonization of Ukrainian normative requirements for water removal at the highway objects with European regulations.

The purpose of the paper is to determine the quantitative characteristics of the pollution of the surface wastewater generated by PPs and their 
fractions at the facilities of the automobile and road complex in the winter and summer seasons, as well as their behaviour during wastewater treatment by mechanical methods.

\section{Objects and methods of experimental studies}

The objects of experimental studies were:

- surface wastewater of the winter season - snow cover formed in the territory of suburban highway facilities;

- surface wastewater of the summer season artificial drains from waterproof coverings of the carriageway of suburban highway facilities.

The snow samples were taken at a distance of $0.5 \mathrm{~m}$ from the boundary line of the roadway of suburban highway facilities on the twelfth day after the snowfall. The samples of surface runoff from the territories of suburban highway facilities were obtained by the method of washing off (the period without rain before sampling was 10-15 days). The washing off was performed with a cotton-wool swab and a certain amount of distilled water from a certain area of the roadway coverage, limited by a wooden palette [6]. In experimental studies, the processes that take place during surface wastewater settling in open and closed containers were modelled. The wastewater under study was placed in graduated beakers and settled for 30 days. To model the systems of closed settling, the beakers were covered with plastic caps. In the winter period, settling was performed in the laboratory at a temperature of $150{ }^{\circ} \mathrm{C}$ and air velocity of $0.1 \mathrm{~m} / \mathrm{s}$, in the summer period - at a temperature of $22-26{ }^{\circ} \mathrm{C}$ and air velocity of $0.5-2 \mathrm{~m} / \mathrm{s}$. Water samples, a supernatant fluid, were taken by the probe without damaging the precipitate and the surface film (in those cases where it was formed).

The content of PPs in the aqueous medium (melted snow) was determined gravimetrically [7]. Petroleum products were extracted from the water by chloroform, then the solvent was removed by evaporation, and the residue was dissolved in hexane and the polar compounds were separated by treatment on a column with aluminum oxide. The solvent was evaporated and the gravimetric mass of the residue was measured [7]. During the analysis, extraction of PPs using only hexane was performed simultaneously [7]. This allowed fractionating of PPs [8] that contaminate surface wastewater, dividing them into a fraction of conditionally aliphatic PPs - gasoline, kerosene, diesel fuel (hexane extract), and a fraction of conditionally complex PPs - of high molecular weight and heteroorganic (the difference between the content of PPs extracted by chloroform + hexane and PPs extracted by hexane only).

Mathematical processing of experimental data, finding of regression equations and surface construction were performed using Microsoft Excel software.

\section{Results of experimental studies}

\subsection{Determination of the content of PPs in surface wastewater generated at suburban facilities in the winter and summer seasons}

The ecological danger of the surface runoff generated during the winter season in the territories adjacent to the suburban highway facilities was estimated by the multiplicity of the excess of MAC of PPs in wastewater discharged to natural reservoirs (0.05 $\mathrm{mg} / \mathrm{dm}^{3}$ [9]) (Fig. 1, 2). As shown by the analysis of the surface runoff of the winter season (snow) from the territories adjacent to the suburban highway facilities (Fig. 1), the content of PPs in the initial samples (taken on the twentieth day after the snowfall) in all studied areas was thousand times larger than the MAC level for water bodies. The largest excess of MAC was found in the surface wastewater taken from the territory of the suburban parking for heavy trucks (4050 MAC). A very high level of pollution of surface runoff by PPs (6701330 MAC) was also found in the territories adjacent to other highway objects: petrol filling station and tire assembly complex. Similar environmentally hazardous surface wastewaters were generated at the highway facilities in the summer period (968-1068 times excess of MAC for PPs) (Fig. 2). The content of PPs in the samples taken directly from the roadway was slightly lower than that at the highway facilities (Fig. 2), but it also significantly exceeded the MAC. The inflow of such wastewater into natural reservoirs is absolutely unacceptable [10].

Thus, it can be noted that at the facilities where transport was static, the content of PPs in drain wastewater by the level of MAC was significantly higher than at the facilities where transport was dynamic (highways). Consequently, transport creates the largest pollutant influence on surface wastewater in the mode of statics and low dynamics (during idle running of engine) compared with transport moving at a relatively higher speed. 


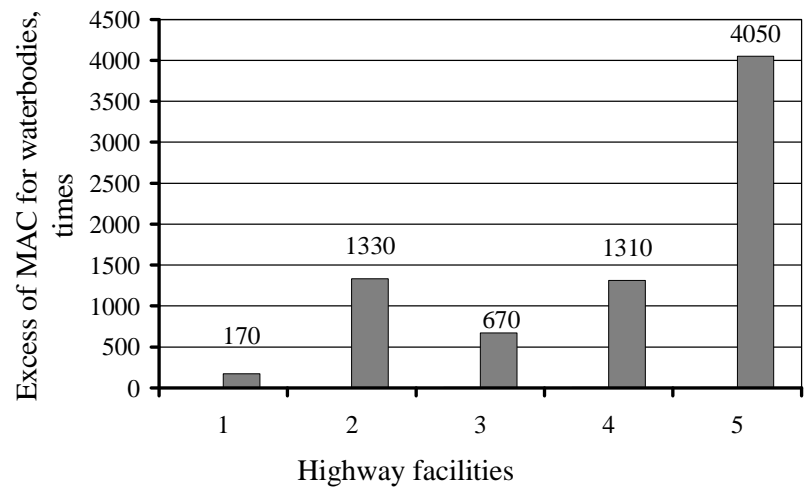

1 - control; 2 - petrol filling station No. 1 ; 3 - petrol filling station No. 2; 4 - tire assembly complex; 5 - parking lot

Fig. 1. Ecological danger of petroleum-containing surface wastewater of the winter season in the territories adjacent to the suburban highway facilities

\subsection{Experimental determination of the efficiency of PPs and their individual fractions removal from surface wastewater during settling}

In the experimental modelling of the mechanical treatment processes, the transformations of PPs contaminating surface wastewater were monitored under open and closed settling (with limited air access). Closed

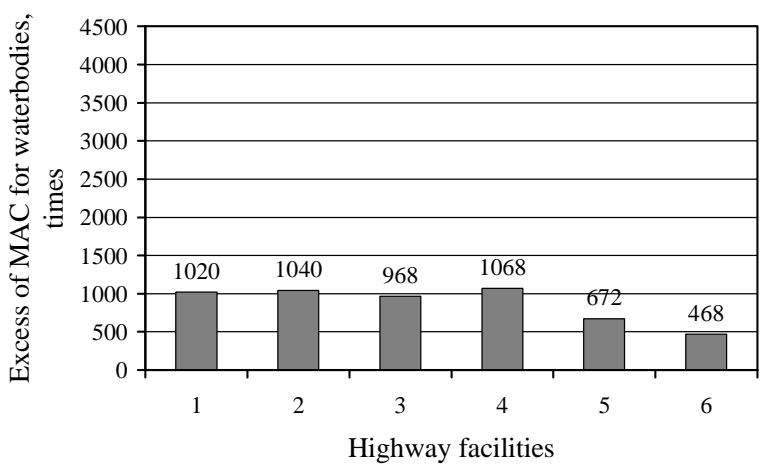

1 - petrol filling station No. 2; 2 - petrol filling station No. $3 ; 3$ - petrol filling station No. 4; 4 - parking lot; 5 - highway R-46; 6 - highway M-03

Fig. 2. Ecological danger of petroleum-containing surface wastewater of the summer season in the territories adjacent to the suburban highway facilities

type of mechanical settling structures is widely used for mechanical treatment of petroleum-containing surface wastewater from the territories of industrial facilities [11]. An assessment of the efficiency of PPs removal in the open and closed settling of surface wastewater in the winter season (initial PPs concentration of $82.4-186.5 \mathrm{mg} / \mathrm{dm}^{3}$ ) was carried out after 30 days of exposure (Table 1).

Table 1

Indicators of treatment of the surface wastewater generated in the territory of suburban petrol filling stations from PPs after settling for 30 days (winter season)

\begin{tabular}{|c|c|c|c|c|c|}
\hline \multirow[b]{2}{*}{ Settling mode } & \multirow{2}{*}{$\begin{array}{l}\text { Residual amount of wastewater in } \\
\text { relation to the initial, \% }\end{array}$} & \multicolumn{3}{|c|}{ Efficiency of water treatment (\%) from } & \multirow{2}{*}{$\begin{array}{c}\text { Mass } \\
\text { of removed } \\
\text { PPs, } \mathrm{mg} / \mathrm{dm}^{3}\end{array}$} \\
\hline & & PPs & $\begin{array}{l}\text { conditionally } \\
\text { aliphatic PPs }\end{array}$ & $\begin{array}{l}\text { conditionally } \\
\text { complex PPs }\end{array}$ & \\
\hline Closed & 100 & 50 & 45 & 77 & 41.1 \\
\hline Open & 70 & $\begin{array}{c}55 \\
(78.6)^{*}\end{array}$ & $\begin{array}{c}63 \\
(90)^{*}\end{array}$ & $\begin{array}{c}12 \\
(17)^{*}\end{array}$ & 44.9 \\
\hline
\end{tabular}

()$^{*}$ - taking into account the reduction of wastewater volume

Theoretically, in the modelled treatment facilities, the decrease in the content of PPs in treated wastewater was mainly due to three processes: evaporation and dispersion of volatile PPs; deposition of suspended and emulsified PPs independently or at adsorption on mineral suspended substances; oxidic destruction of PPs.

After such a long settling in the open system, the volume of liquid as a result of evaporation in various experimental variants decreased by $30-35 \%$. Therefore, the treatment indicators in this variant of the experiments were adjusted taking into account the reduction of the volume of settled liquid. As can be seen from the Table, the efficiency of wastewater treatment from PPs in the open system of settling significantly
(1.3 times) exceeded this indicator in the closed system of settling, especially for the hexane fraction of PPs (almost 2 times). The increase after the open settling of the conditionally complex fraction of PPs extracted by chloroform + hexane is, probably, due to the accumulation of hydrocarbon oxidation products in the environment - heteroorganic compounds that are not extracted by hexane.

Thus, the open settling of surface wastewater, which provides active air exchange contributing to the evaporation and dispersion of volatile PPs, as well as the sufficient amount of oxygen for oxidative destruction of PPs by microorganisms, is better for the treatment of surface wastewater generated at suburban highway 
facilities from PPs. Therefore, further experimental studies of mechanical treatment of surface wastewater were performed in the open settling mode. It was established that the duration of settling should not exceed 7-10 days (especially in the summer season), since during long-term settling on the surface of the liquid a dense biofilm is formed which prevents free air penetration and creates conditions for closed settling that adversely affects the efficiency of treatment from PPs [12].

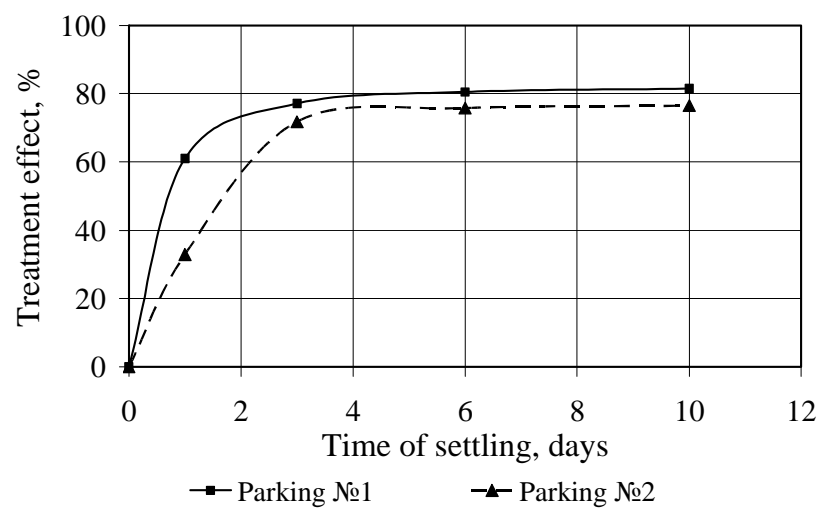

Fig. 3. Efficiency of treatment of surface wastewater, generated in the territory of suburban parking lots, from PPs

During settling (Fig. 4), the concentration of fraction of conditionally complex PPs gradually reduced (treatment effect is 94\%), while the concentration of the fraction of conditionally aliphatic PPs stabilized in almost 1 day, with a low treatment effect of $20 \%$. Thus, the effect of treatment of surface wastewater generated during the summer season from PPs (as opposed to treatment of the surface wastewater of the winter season) during the settling was predominantly due to the removal of fraction of conditionally complex PPs represented by possibly different heteroorganic compounds of PPs. This difference is probably due to the influence of the temperature factor.

For the mathematical description of the treatment process of surface wastewater during settling, the effect of two processing factors (initial concentration of PPs and time of settling) on the effect of purification from PPs were considered, taking into account their fractional composition.

The theoretical equation describing this real process takes the form of exponential dependence:

$$
y=\frac{A}{B \cdot e^{t}}+C,
$$

where $A$ - initial concentration of PPs $\left(\mathrm{C}_{\mathrm{H}}\right) ; e-$ exponential constant $=2.7 ; t-$ time of settling, days; $C-$ coefficient that determines the residual level of PPs,
The dynamics of the efficiency of surface wastewater treatment formed at suburban parking lots from PPs for the open settling is presented in Fig. 3. As it can be seen, on the third day of surface wastewater settling, the effects of treatment from PPs in the samples practically stabilized $(75-80 \%)$. During the settling in the wastewater under treatment, not only the total content of PPs varied, but also the ratio of PPs fractions conventionally aliphatic and complex ones (Fig. 4).

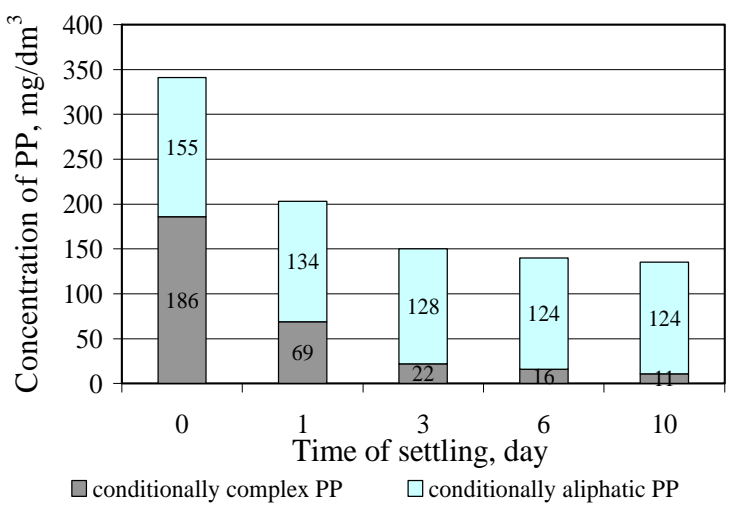

Fig. 4. Dynamics of the fractional composition of PPs in surface wastewaters generated in the territory of suburban parking lots during the settling

which does not change in the process of further settling (that is, at the maximum effect of treatment);

$\mathrm{B}$ - coefficient that provides a curve compression between the values $A$ and $C$, which is determined by formula 2:

$$
B=\frac{C_{\mathrm{H}_{0}}}{C_{\mathrm{H}_{0}}-C} .
$$

After analysis of the experimental data, it can be stated that in all experiments, the final content of PPs after settling is different and has a quadratic dependence on the initial content of PPs (Fig. 5).

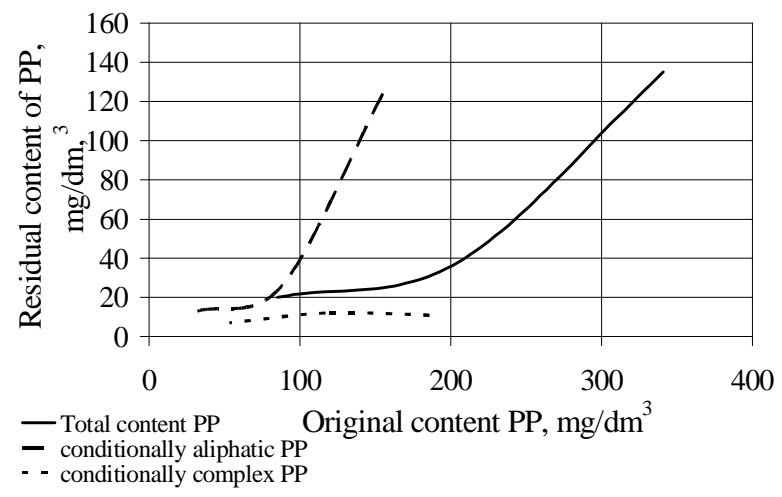

Fig. 5. Dependence of the final content of PPs on the derivative concentration of PPs in the settled surface wastewater 
In general, it can be represented as the common square equation:

$$
C_{i}=a \cdot C_{i \Pi_{0}}{ }^{2}-b \cdot C_{i \Pi_{0}}+d,
$$

where $i$-conditional number of the fraction of PPs; $a, b$, $d$ - coefficients of the equation.

Let's define the coefficients of the regression equation to calculate the coefficient $\mathrm{C}$ from equation (1) (formulas 4 to 6), which determine the residual level of PPs depending on the initial level of PPs.

For total PPs $\left(C_{1}\right)$

$$
\begin{aligned}
& C_{1}=0.0022 \cdot C_{1 \mathrm{H}_{0}}{ }^{2}- \\
& -0.488 \cdot C_{1 \mathrm{H} \Pi_{0}}+45.587,
\end{aligned}
$$

where $C_{1 \mathrm{H}_{0}}$ - initial concentration of total PPs.

For the fraction of conditionally aliphatic PPs $\left(\mathrm{C}_{2}\right)$

$$
\begin{aligned}
& C_{2}=0.01 \cdot C_{2 \mathrm{H \Pi}_{0}}{ }^{2}- \\
& -0.9684 \cdot C_{2 \Pi_{0}}+33,744,
\end{aligned}
$$

where $C_{2 \Pi_{0}}$ - initial concentration of fraction of conditionally aliphatic PPs.

For the fraction of conditionally complex PPs $\left(\mathrm{C}_{3}\right)$

$$
\begin{aligned}
& C_{3}=-0.007 \cdot C_{3 \mathrm{H \Pi}_{0}}{ }^{2}+ \\
& +0.1965 \cdot C_{3 \mathrm{H}_{0}}-1.4588,
\end{aligned}
$$

where $C_{3 \Pi_{0}}$ - initial concentration of fraction of conditionally complex PPs.

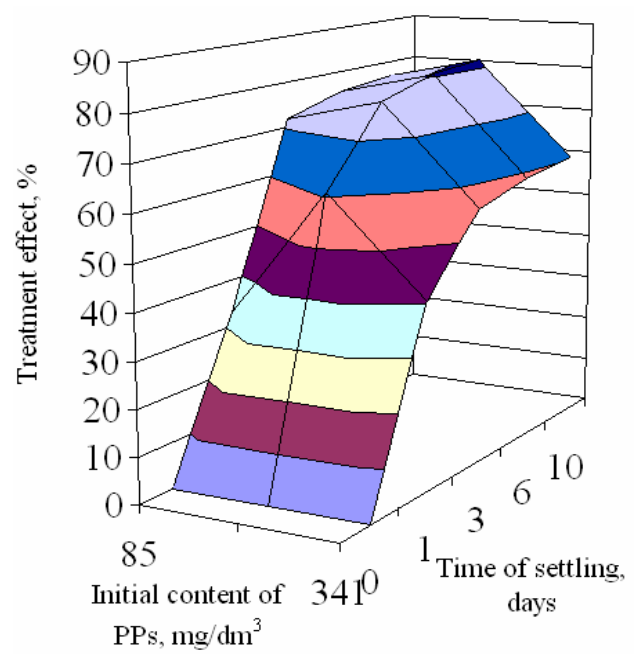

a) averaged experimental data
The final dependence, which determines the content of PPs in the sample, depending on the time of settling with different initial content of PPs, is represented in the general form by the expression 7 .

$$
C_{i \mathrm{H} \Pi}=\frac{C_{i \mathrm{H}_{0}}}{\frac{C_{i \Pi_{0}}}{C_{i \Pi_{0}}-C_{i}} \cdot e^{t}}+C_{i} .
$$

The effect of treatment $(\mathrm{E})$ is determined based on the initial content of PPs and current one at a certain point in time (dependence 8)

$$
E_{i}=\frac{C_{i \Pi_{0}}-C_{i \mathrm{H} \Pi}}{C_{i \Pi_{0}}} \cdot 100 \% .
$$

Based on experimental data (initial content of PPs 84-341 $\mathrm{mg} / \mathrm{dm}^{3}$, time of settling - 0-10 days) and calculation formulas, graphical representation of the surface was developed, which determines the relationship between the effect of surface wastewater treatment from PPs at parking lots and the time of settling with different initial content of PPs (Fig. 6-8).

The results of calculating the relative error of the total concentration of PPs, fractions of conditionally aliphatic PPs, fractions of conditionally complex PPs in the dynamics of settling of surface wastewater are presented in Tables 2-4.

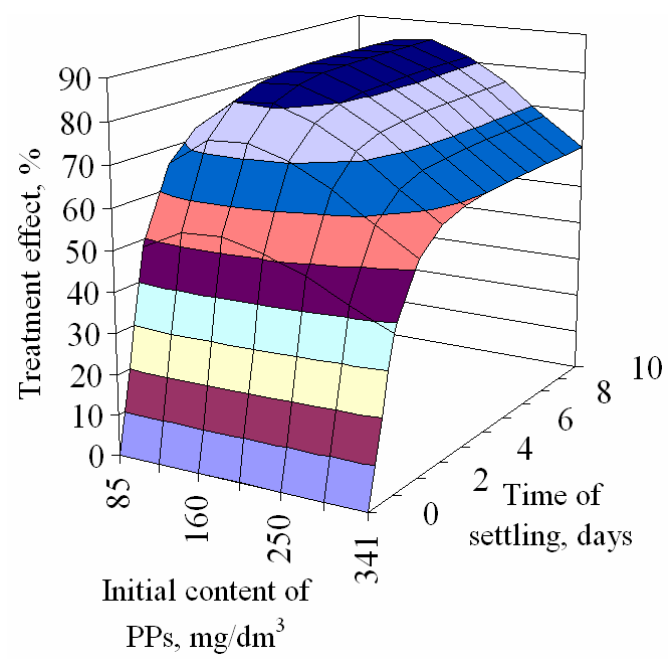

b ) surfaces obtained according to dependencies $(7,8)$

Fig. 6. Surfaces that determine the dependence of the effect of PPs removal from surface wastewater on the time of settling and the initial concentration of PPs

Rather large values of the relative error of theoretical calculations on the first day of settling are, probably, due to the influence of unconsidered factors (for example, the sedimentation of suspended substances), which during the further settling were absent. After the third day the error is $2-12 \%$.
According to the theoretical surface (Fig. 6, $b$ ), it is possible to estimate the range of the most effective removal of PPs from surface wastewater in the territories of suburban parking lots. Calculations have shown that the highest effect of treatment from PPs (within the range of 85 to $341 \mathrm{mg} / \mathrm{dm}^{3}$ ) is achieved with 
the initial concentration of PPs in the range of 125 to $210 \mathrm{mg} / \mathrm{dm}^{3}$ on the third day of settling.

Based on the theoretical surface (Fig. 7, b), it is possible to estimate the range of the greatest efficiency of removal of conditionally aliphatic PPs fraction from the surface wastewater generated in the territory of suburban parking lots. Calculations have shown that the highest effect of treatment from the conventionally aliphatic fraction of PPs (within the range of 32 to $155 \mathrm{mg} / \mathrm{dm}^{3}$ ) is achieved with the initial concentration of PPs in the range of 45 to $88 \mathrm{mg} / \mathrm{dm}^{3}$ on the second or the third day of settling.

Relative error of calculated concentrations of PPs in settling surface wastewater

\begin{tabular}{|c|c|c|c|}
\hline \multirow{2}{*}{ Time of settling } & \multicolumn{3}{|c|}{$\begin{array}{c}\text { Relative error of theoretical calculations (\%) } \\
\text { at the initial concentration, } \mathrm{mg} / \mathrm{dm}^{3}\end{array}$} \\
\hline & 341 & 205 & 05 \\
\hline 0 & 0 & 0 & -46.34 \\
\hline 1 & 6.08 & 15.92 & -1.09 \\
\hline 3 & -2.40 & -0.29 & -1.29 \\
\hline 6 & -2.30 & -0.93 & 0.05 \\
\hline
\end{tabular}

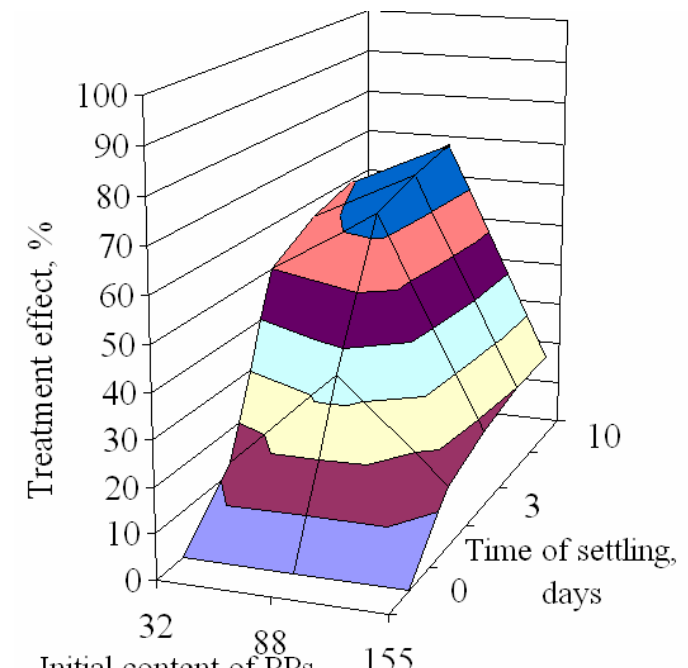

Initial content of PPs, 155 $\mathrm{mg} / \mathrm{dm}^{3}$

a) averaged experimental data

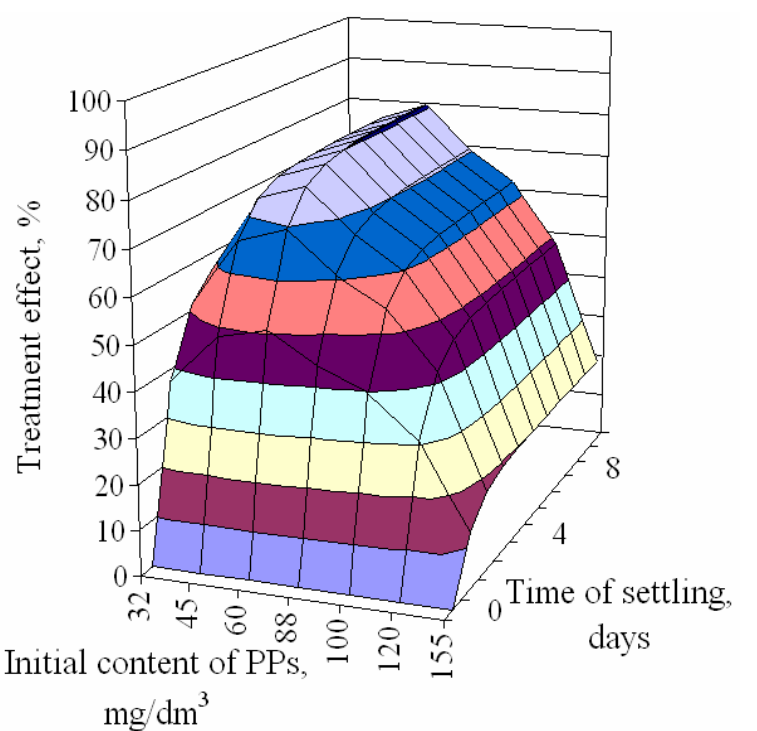

b) surfaces obtained according to dependencies $(7,8)$

Fig. 7. Surfaces that determine the dependence of the effect of removal of conditionally aliphatic fractions of PPs from surface wastewater on the time of settling and the initial concentration of the fraction of conditionally aliphatic PPs

According to theoretical surface (Fig. 8, b), it is possible to estimate the range of the greatest efficiency of removal of the fraction of conditionally complex PPs from surface wastewater from the territories of parking lots. Calculations showed that the highest effect of treatment from the conventionally complex fraction of PPs (within the study range of 53 to $186 \mathrm{mg} / \mathrm{dm}^{3}$ ) is achieved at the initial concentration of PPs in the range of 134 to $186 \mathrm{mg} / \mathrm{dm}^{3}$ on the second or the third day of settling.

As it can be seen, as in the previous calculation (Table 2), relatively large values of error of theoretical calculations at the first and the third day of settling are observed, especially at the lowest initial concentration of aliphatic PPs $32 \mathrm{mg} / \mathrm{dm}^{3}$. 
Relative error of calculated concentrations of conditionally aliphatic PPs fraction

\begin{tabular}{|c|c|c|c|}
\hline \multirow{2}{*}{ Time of settling } & \multicolumn{3}{|c|}{$\begin{array}{c}\text { Relative error of theoretical calculations (\%) } \\
\text { at the initial concentration, } \mathrm{mg} / \mathrm{dm}^{3}\end{array}$} \\
\hline & 155 & 88 & 32 \\
\hline 0 & 0 & 0 & -199.15 \\
\hline 1 & 6.4 & -26.1 & -12.75 \\
\hline 6 & -9.5 & -3.3 & -5.22 \\
\hline 10 & -0.09 & -3.1 & 0.02 \\
\hline
\end{tabular}

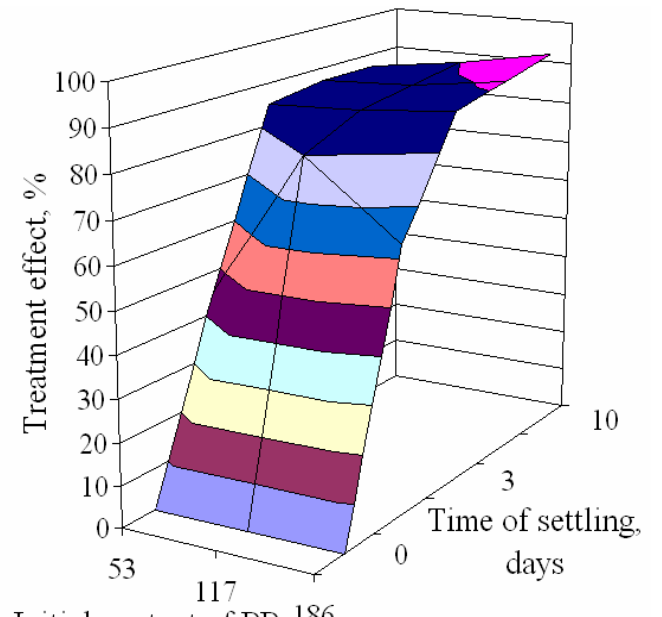

Initial content of PPs, ${ }^{186}$

$\mathrm{mg} / \mathrm{dm}^{3}$

a) averaged experimental data

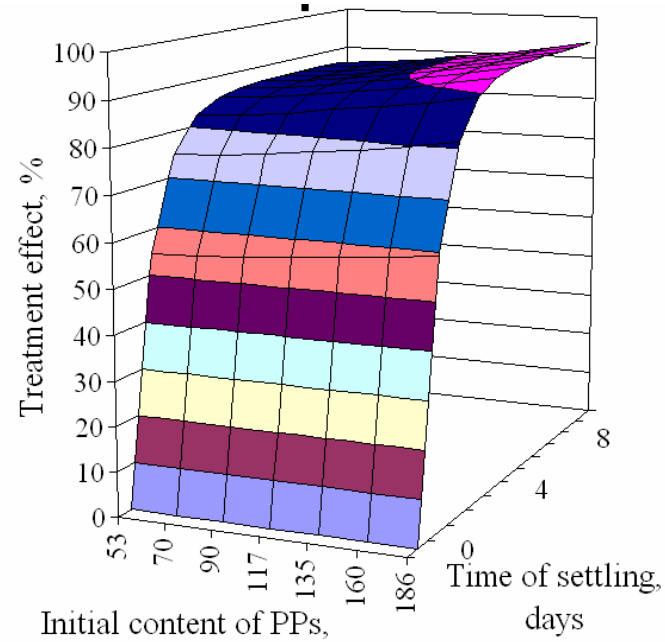

narpamms $\mathrm{mg} / \mathrm{dm}^{3}$

b) surfaces obtained according to dependencies $(7,8)$

Fig. 8. Surfaces that determine the dependence of the effect of removal of the fraction of conditionally complex PPs from surface wastewater on the time of settling and the initial concentration of fraction of conditionally complex PPs

Relative error of calculated concentrations of fraction of conditionally complex PPs

\begin{tabular}{|c|c|c|c|}
\hline \multirow{2}{*}{ Time of settling } & \multicolumn{3}{|c|}{$\begin{array}{c}\text { Relative error of theoretical calculations (\%) } \\
\text { at the initial concentration, } \mathrm{mg} / \mathrm{dm}^{3}\end{array}$} \\
\hline & 186 & 117 & 53 \\
\hline 0 & 0 & 0 & -21.5 \\
\hline 3 & 5.9 & 29.33 & 3.06 \\
\hline 6 & -1.56 & 0.9 & 0.47 \\
\hline 10 & -3.2 & -1.77 & 0.22 \\
\hline
\end{tabular}

As in the previous calculations (Tables 2, 3), on the first day of settling, there are the greatest errors in the calculation of the concentration of PPs fraction. On the third day of settling, absolute values of the error of the fraction of conditionally complex PPs are significantly lower than that of the fraction of aliphatic PPs.

The theoretical surfaces adequately reflect the results of the experiment.

\section{Conclusions}

According to the data obtained, the most environmentally hazardous surface wastewater (by the multiplicity of excess of MAC of PPs) is generated in the territory of suburban highway facilities, where transport is stationary or moves at a low speed. 
In experimental studies, the open settling of surface wastewater compared with the system of closed settling 1.3 times increases the effect of PPs removal and hexane fraction of PPs - almost 2 times.

The duration of the open settling of surface wastewater generated in the territory of suburban parking lots should be 3-10 days.

Regression equations that describe the dependence of the effect of surface wastewater treatment from PPs on 2 factors (initial concentration of PPs and the time of settling) were developed. The highest effect of treatment from PPs (within the studied range) was achieved with the initial PPs concentration of 125 to $210 \mathrm{mg} / \mathrm{dm}^{3}$ on the third day of settling.

\section{References}

[1] Korovina Ye. V., Satarov G. A., Scientific Journal "Modern High Technologies", 2009, 3, 17. (in Russian)

[2] Dolmatova L. A., Guseva M. A., Polzunovsky vestnik, 2004, 2, 150. (in Russian)

[3] Pikovskiy Yu. I., Glazovskoy M. A., Vosstanovleniye Neftezagryaznennykh Pochvennykh Ekosistem [Restoration of petroleum-contaminated soil ecosystems]. Series Modern problems of the biosphere, Nauka, Moscow 1988, 7-22. (in Russian)
[4] Motenko R. G., Kiryukhina T. A., Geraskina E. V., Natitnik I. M., Lazareva E.V. Proceedings of the International Conference "City and Geological Hazards”. Russia, 2006, 117. (in Russian)

[5] Polkowska Ż., Skarżyńska K., Dubiella-Jackowska A., Staszek W., Namieśnik J., Global NEST Journal., 2007, 9, No. 3, 269. (Gdansk Beltway, Poland).

[6] DBN V.2.5. - 75: 2013 Sewerage. Outdoor networks and structures. Basic Design Provisions (in Ukrainian)

[7] Lurie Yu. Yu., Analiticheskaya Khimiya Promyshlennykh Stochnykh Vod [Analytical chemistry of industrial wastewater], Khimiya. Moscow, 1984. (in Russian)

[8] http://www.ich.dvo.ru/ isse/2011/images/stories/ files/extraction.pdf

[9] The rules No. 465 on protection of surface water from pollution by return water, approved by the decision of the Cabinet of Ministers of Ukraine, dated March 25, 1999.

[10] Melnikova O. G., Iurchenko V. A., Artemenko A. V. Collection of Works of the VI International Congress. Chistaya Voda. Kazan, 2015, 98. (in Russian)

[11] Dolina L. F. Sovremennaya Tekhnologiya i Sooruzheniya Dlya Ochistki Neftesoderzhashchikh Stochnykh Vod [Modern Technology and Facilities for the Treatment of Petroleum-Containing Wastewater]. Kontinent, Dnepropetrovsk, 2005. (in Russian)

[12] Iurchenko V. A., Artemenko A. V., Melnikova O. G., Naukovyy Visnyk Budivnytstva - Scientific Bulletin of Civil Engineering, 2015, 2(80), 219. (in Ukrainian) 